\title{
Lambs and landscapes
}

\author{
A.D. MACKAY ${ }^{1}$, T.W. KNIGHT ${ }^{1}$, J.P. KOOLAARD ${ }^{1}$, G. SHEPPARD ${ }^{2}$ and G. COLEMAN ${ }^{3}$ \\ ${ }^{1}$ AgResearch, Grasslands Research Centre, PB 11008, Palmerston North \\ ${ }^{2}$ Sheppard Agriculture Ltd, PO Box 232, 12 Ward St, Dannevirke \\ ${ }^{3} R D 3$ Dannevirke \\ alec.mackay@agresearch.co.nz
}

\begin{abstract}
Hill country farmers face major challenges to provide the physical environment and climatic conditions for maximum survival of multiple-born lambs. Farmers and scientists together investigated the opportunities for improved lamb survival on seven high-producing (scanning percentage 150-220\%) North Island hill country farms. For 3 years, each of the participating farmers monitored lamb survival to docking on their farms. Five paddock attributes (e.g. slope, hazards, disturbance, wetness and wind) were quantified, weighted and summed to provide a paddock score. When all the lamb docking data (2005-2008) were pooled, the relationship between paddock score (slope thazards + disturbance +wetness + wind) and lamb survival to docking was not significant $\left(\mathrm{y}=-0.983 \mathrm{x}+181, \mathrm{R}^{2}=\right.$ 0.186 ). This was in part due to the mild conditions that prevailed during spring each year. Despite the poor relationships, the land assessment tool (LAT) developed provides a stepwise basis for examining how different paddocks tend to affect lamb survival to docking and why the performance might vary from year to year.
\end{abstract}

Keywords: lamb survival, physical environment, land assessment tool

\section{Introduction}

Lambing percentage of New Zealand's sheep flock has been improving annually (Agriculture and Forestry in New Zealand 2003). Top performing sheep farmers are now consistently achieving well in excess of $150 \%$ survival to weaning. Ram selection, improved nutrition and overall animal management (e.g. disease control, mid pregnancy shearing) and technologies (scanning) have driven this increase. The use of pregnancy scanning has also enabled farmers to identify the efficiency of their lambing programmes.

On hill country, there is limited access to easy contoured land protected from the extremes of climate. As the proportion of the breeding ewe flock bearing twins and triplets increases with scanning percentages over $150 \%$, there are not enough paddocks for set stocking on ideal lambing country. Knight et al., (1988) showed with twin bearing ewes that, as slope increased above $30^{\circ}$, lamb mortality rates increased exponentially due to lambs slipping from the birth site. With that knowledge available, the practice of spreading ewes out across the whole farm just prior to lambing becomes less and less of an option, as the proportion of the farm suitable for lambing (flat and easy) decreases. Knowingly shedding out multiple bearing ewes onto hill country and accepting high mortality rates is neither good business, nor does it represent responsible management. With an eye to ongoing profitability of hill country farming and to future market access we need to develop a suite of tools to lift lamb survival.

We investigated what the opportunities are for improving lamb survival on seven sheep farms in North Island hill country with scanning percentages ranging from $150-220 \%$. The effect of different landscape and environmental features (e.g. slope, hazards, wetness, etc) on lamb survival from multiple bearing ewes was quantified and the potential for improving lambing survival by a change in management explored.

\section{Method}

\section{On-farm study}

For 3 years (2005-08), each of seven participating farmers recorded lamb and ewe numbers at docking on three separate blocks on their farm. Farms are located from the foot hills of the Ruahine Range near Dannevirke to Herbertville on the East Coast. The farms ranged from typically summer moist to summer dry hill country environments with a range in dominant aspect and altitudes. Treatment blocks were picked to represent areas of the farm that were viewed as "good", "average" or "poor" for lamb survival from multiple bearing ewes. Blocks were stocked 4 to 14 days prior to lambing with twin bearing ewes of the same age, breed and mean lambing date. Ewes had been mated to the same group of rams and grazed together up to set stocking before lambing. Lamb losses were calculated from the difference between the actual scanning percentage $(200 \%)$ and the number of lambs present at docking. Ewe deaths were calculated from the difference between ewes set stocked and present at docking (Table 1).

\section{Development of the land assessment tool}

The paddocks used by each farmer in the group had a range of aspects, shelter, slope, evenness, wetness and potential disturbance, all factors influencing lamb survival. 
Table 1 Examples of the type of data collected from each lambing block.

\begin{tabular}{|c|c|c|}
\hline & Airstrip/Yard & Hora Tai Tumu \\
\hline Data logger \# & 14 & 5 \\
\hline Dam breed & Texel/Romney & Composite \\
\hline Sire breed 1 & Texel/Romney & Kelso/Terminal \\
\hline Lambing date & 25 August 2006 & 5 September 2006 \\
\hline Scanning percentage & 151 & 200 \\
\hline Date shorn & Feb & NA \\
\hline Nitrogen date \#1 & & 24 August 2006 \\
\hline Nitrogen rate $(\mathrm{kg} / \mathrm{ha})$ & & 20 \\
\hline Androvax & Y & $\mathrm{N}$ \\
\hline Toxovax & $\mathrm{Y}$ & HGT \\
\hline Campy & Y & HGT \\
\hline 5 in 1 & Y & Y \\
\hline Trace elements $(\mathrm{Cu}, \mathrm{Se}, \mathrm{I})$ & Y & $\mathrm{N}$ \\
\hline Pre-lamb drench & Nilvax & Lightest ewes \\
\hline Last udder check & & 1 February 2006 \\
\hline \multicolumn{3}{|l|}{ Animal data } \\
\hline No. of ewes & 200 & 166 \\
\hline Age structure & 2th, MA & MA \\
\hline Ewe condition score at set stock & 3 & 2.5 \\
\hline \multicolumn{3}{|l|}{ Number single foetuses } \\
\hline \multirow{2}{*}{\multicolumn{3}{|c|}{ Number triplet foetuses }} \\
\hline & & \\
\hline Potential number of lambs & 400 & 332 \\
\hline \multicolumn{3}{|l|}{ Animal performance } \\
\hline Number of lambs at docking & 299 & 274 \\
\hline Number of wet ewes at docking & 176 & 153 \\
\hline Number of dry ewes at docking & 8 & 8 \\
\hline Number of ewes removed at docking & 8 & 8 \\
\hline Number of ewes dead by docking & 7 & 5 \\
\hline Number of ewes not accounted for & 9 & 0 \\
\hline$\%$ of dead ewes & 3.5 & 3.0 \\
\hline$\%$ Lambs lost due to ewe deaths & 3.5 & 3.0 \\
\hline Paddock docking $\%$ (ewes at set stocking) & 150 & 165 \\
\hline$\%$ Lambs dead per lamb scanned (ewes set stocked) & 25.3 & 17.5 \\
\hline$\%$ Lambs dead per lamb scanned (ewes alive at docking) & 22.5 & 14.9 \\
\hline Ewe condition score at docking & 3 & 2.3 \\
\hline
\end{tabular}

Table 2 Criteria and recording sheet for making a visual assessment of a lambing paddock.

\section{Farm name}

\section{Paddock name}

Slope $\%$ of paddock area with slope $>26^{\circ}$

Hazards \% of paddock area affected by:

Fences on narrow ridges

Fences across steep slopes (x 2 weighting)

Bluffs \& dropouts

Waterways \& Drains

Steep land on sides of water courses (x 2 weighting)

Ponds/dams, lakes and swamps

Disturbance Major $=5$, none $=1$

Wetness Well, imperfectly or poorly drained

Land class Flat, rolling, hill or steep

\section{Shelter}

$\%$ of paddock area with vegetation shelter

'Killer' wind (e.g. southerly)

$\%$ of paddock area with landscape/aspect protection from killer wind 
Figure 1 Relationship between (a) paddock score with only slope and hazards included and lamb survival to docking on the participating farms in 2006 and (b) paddock score with all the factors included (slope +hazards +disturbance + wetness +wind) and lamb survival to docking on the participating farms in 2006. (n.s. $=$ not significant, $\left.{ }^{*} \mathrm{P}<0.05\right)$.
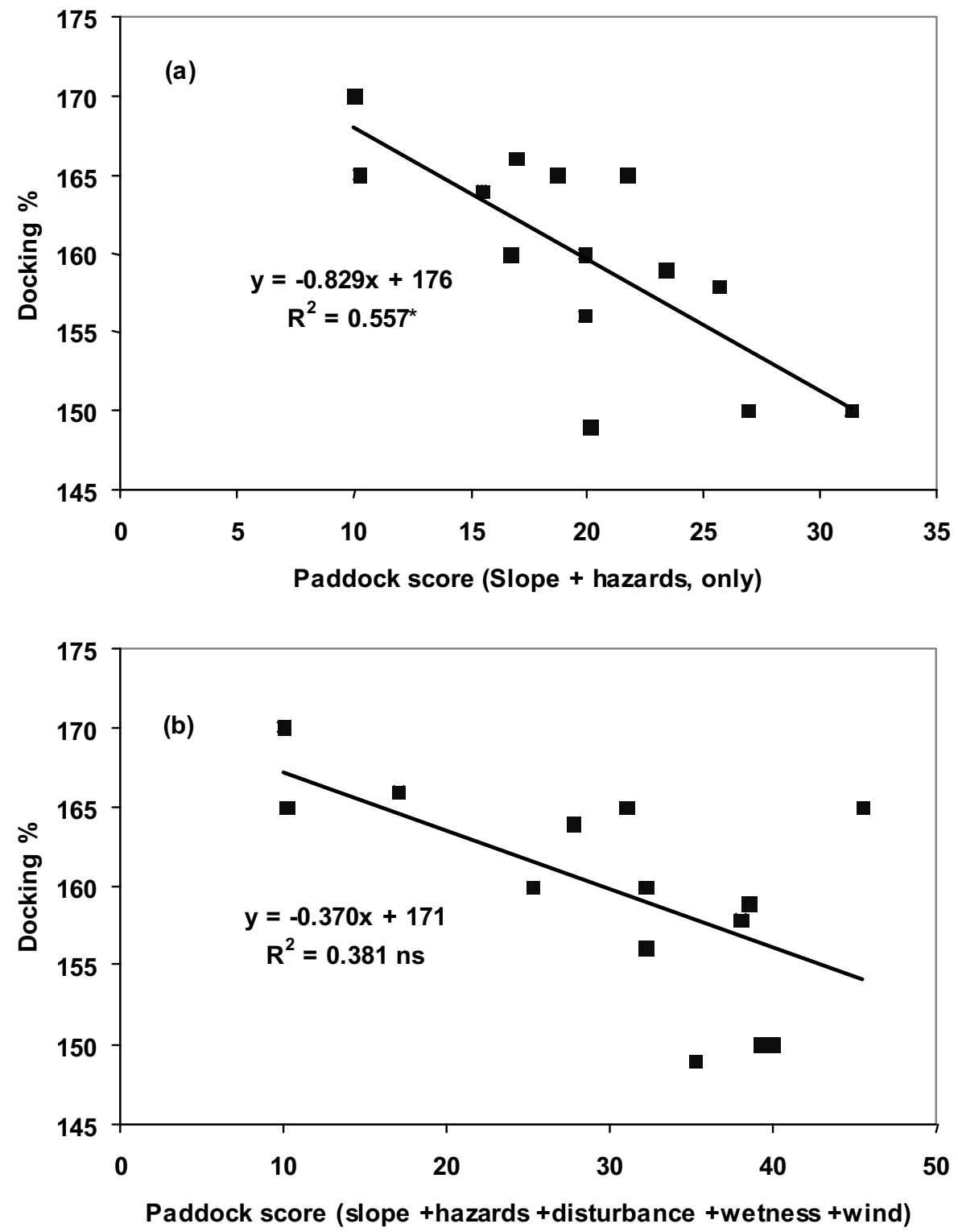

The criteria listed below to characterise and score each paddock, was developed with the farmer group over the first 2 years of the study.

1. Slope Percentage of the paddock area with slope $>26^{\circ}$

2. Hazards Percentage of the paddock area affected by:

- Fences located on narrow ridge tops (weighting x1)

- Fences across slopes $>26^{\circ}$ (weighting x2)

- Bluffs and dropouts (weighting x1)

- Waterways and drains (weighting x1)

- Land $>26^{\circ}$ on both sides of water courses (weighting $\times 2$ )
- Ponds/dams, lakes and swamps (weighting x1).

3. Disturbance Level of disturbance that sheep are exposed to (beside major road $=5$, remote $=1$ ).

4. Wetness Categorise the paddock as 'well drained', 'imperfectly drained' or 'poorly drained'.

5. Land class Categorise the paddock as 'flat', 'rolling', 'hill' or 'steep'. Estimate the percentage of the paddock that has physical protection from the main wind direction that causes lamb losses.

6. Shelter Estimate the percentage of the paddock area 
that has shelter by way of vegetation, excluding shelter (e.g. rushes) in wet areas.

The data collected on each of the factors listed in Table 2 were incorporated into a spreadsheet in a stepwise manner with the features present each year (e.g. slope, hazards and level of disturbance) entered first, followed by those factors influenced by the weather conditions that prevail in an average year (e.g. wetness and wind). Each of the attributes (e.g. slope, wetness, etc) were then given a weighting based on their estimated impact on lamb survival, with those that killed lambs x10 and those that reduced lamb survival $x 5$.

The 2006 data, the most complete data set of the 3 years, was used to compare the relationship between the physical features (slope + hazards) and lamb survival to docking and all five paddock features (slope +hazards +disturbance +wetness +wind) with lamb survival to docking (Fig. 1). There were missing data from farms in 2005 and 2007, limiting analysis to a combination for the 3 years.

\section{Wind chill factor}

In spring 2006, air temperature recordings were taken from lambing blocks (Fig. 2). On each farm, a temperature data logger was stapled to the top of a fence post in the designated trial paddocks. The data loggers were then capped with a block of wood to ensure consistency of measurement across lambing blocks. From these data, the wind chill factor $(\mathrm{CF})$ was calculated from the equation of Donnelly (1984):

$C F=(11.7+3.1 * V$ wind $) *(40$-temp $)+481+$ $418 *(1$-exponential $(-0.04 *$ rain $))$ where $\mathrm{CF}=\mathrm{KJ} / \mathrm{m}^{2} / \mathrm{h}$, wind $=\mathrm{m} / \mathrm{s}$, temperature $={ }^{\circ} \mathrm{C}$ and rainfall $=\mathrm{mm} /$ day, using temperature data collected every 2 hours from 9 September to 1 November 2006 from each paddock. Dannevirke meteorological data from same period recorded a mean rainfall in 24 hours $(\mathrm{mm} /$ day) of 2.9 $\mathrm{mm} /$ day with a min and max of 0 and $27 \mathrm{~mm} /$ day and wind runs ( $\mathrm{km} / 24$ hours) of 2.66 and min and max of 0.5 and $7.5 \mathrm{~m} / \mathrm{s}$. The minimum temperature recorded each day on each lambing block was used with the Dannevirke meteorological data for each day to calculate the chill factor to identify the number of days with the chill factor greater than $1171 \mathrm{KJ} / \mathrm{m}^{2} / \mathrm{h}$. Since the rainfall and wind runs were from only one site, the chill factor comparisons for each lambing block on each farm were based on temperature differences only (Fig. 2).

\section{Return on investment from increasing lamb survival}

A simple excel spreadsheet was used to calculate the breakeven point (using a nominated return on investment) from an investment into changes in the physical environment (e.g. realigning fences, and or adding shelter and improving drainage) for the purpose of improving lamb survival to docking. The model farm for this exercise covered 400 ha and carried $2200 \mathrm{MA}$ ewes. Average ewe pregnancy scanning was $165 \%$,

Figure 2 Air temperatures during lambing on a selection of the paddocks on the participating farms in spring 2006.

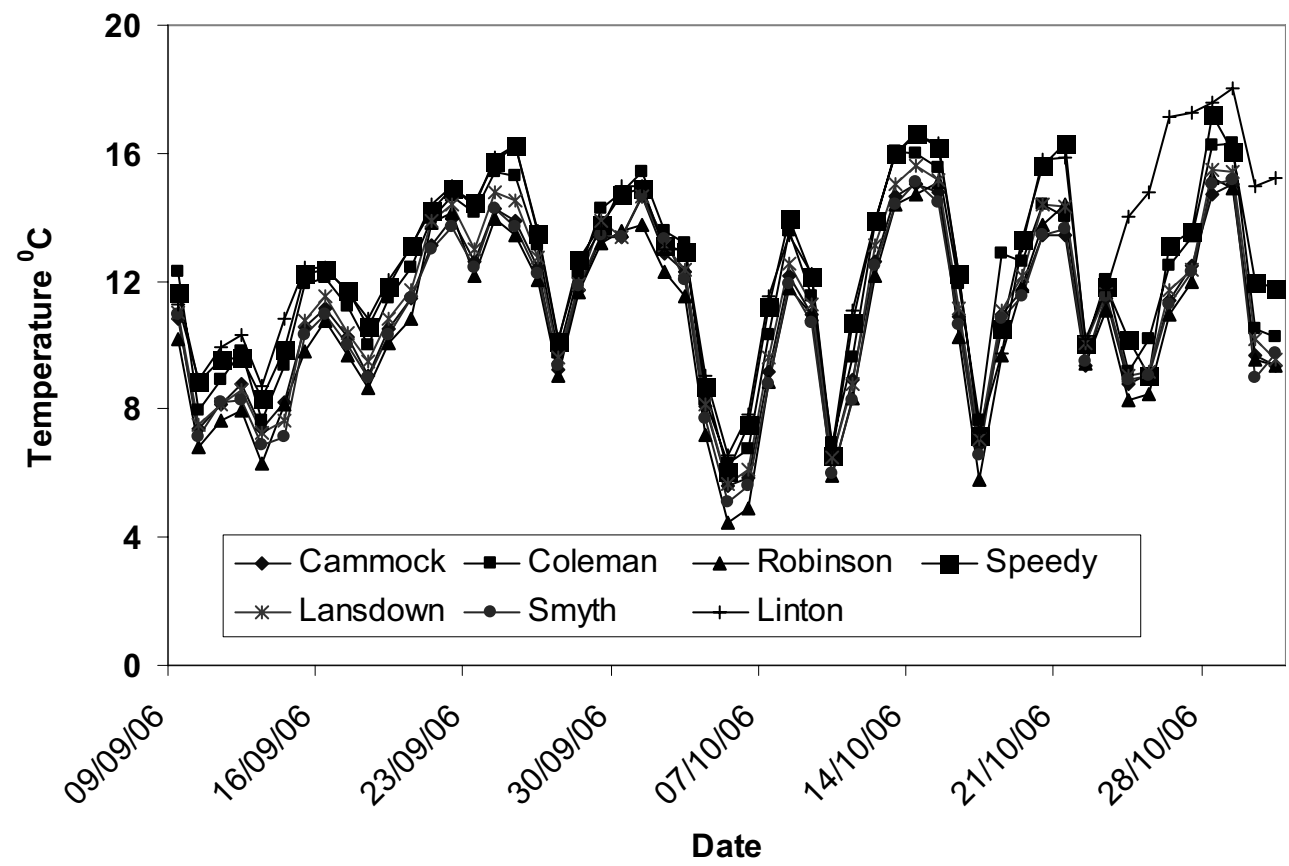


with 1500 multiple bearing ewes. Average lambing percentage was $129 \%$ (2835 lambs), a $22 \%$ lamb wastage from scanning.

\section{Results and Discussion \\ Relationship between paddock features and lamb survival}

The process of scoring the features of each of the three lambing blocks on each farm was conducted in the field with the participating farmers. It proved to be one of the benefits of the project. The process of assessing the lambing paddocks, using the criteria set out in Table 2, created the opportunity to systematically examine why different paddocks tend to perform better or worse in terms of lamb survival to docking and why the performance might vary from year to year.

Visual assessment of the significance by area of various paddock features (e.g. the percentage of a paddock that has slope $>26 \%$, or the percentage of a paddock that is protected from the 'killer wind' by way of contour/aspect) was sometimes quite difficult. There may be a role here to aid assessment through the use of technologies (e.g. terrain models, 3-D visualisations) in the future.

The relationship between lamb survival to docking in 2006 and, respectively, the physical features (slope + hazards) of the paddock, and the combined features that contributed to the paddock score (slope + hazards + disturbance + wetness + wind), are presented in Figures $1 \mathrm{a}$ and $1 \mathrm{~b}$. As the paddock score increased, the suitability of that paddock for lambing declined. Adding wetness and a wind chill factor in 2006, however, weakened the relationship (Fig. 1b). This may be due in part to the mild climatic conditions that prevailed across the participating farms in 2006, despite significant altitude (sea level to $550 \mathrm{~m}$ above sea level) and distance separation $(70 \mathrm{~km})$. The number of days in spring when the calculated wind chill factor could have caused hypothermia varied from only 4 to 10 days across the participating farms that year. In fact, a feature of the 3 years (2005-2008) that lambing data were collected was the favourable weather conditions that prevailed each spring, although ewes endured the wettest winter in 30 years in 2006 and ewe condition was compromised in spring 2007 by dry conditions that prevailed throughout much of the previous summer and autumn. Had "average" weather conditions prevailed, the paddocks with the higher scores could be expected to have lower docking percentages.

When all the lamb docking data (2005-2008) were pooled, the relationship between the paddock score (slope + hazards +disturbance + wetness + wind) and lambs docked was poor and not significant $(\mathrm{y}=-$ $\left.0.983 x+181 ; R^{2}=0.186\right)$. Three factors are likely to have influenced this result. First we used 'average' weather data in three mild springs so lamb losses due to wetness and wind chill were probably lower, even in paddocks with a poor history of lamb survival. Secondly, most farms did not scan for triplets, so actual lamb losses may have been higher than calculated on some paddocks since we used $200 \%$ scanning. Finally, for any paddock score, docking percent varied by at least $20 \%$. Increasing the number of paddocks in the study would have helped strengthen the relationship especially with mild spring conditions. Only environmental factors are examined here.

\section{Land assessment tool}

The land assessment tool (LAT) developed in this study provides a stepwise basis for separating the effect of physical environment (i.e. slope and hazards) from the impacts of the weather conditions (i.e. wetness and wind) prevailing over a particular lambing. For example, is there merit in re-aligning fences to remove hazards, employing temporary fencing to remove steep faces, planting shelter trees or lambing on the safest country (identified by the LAT approach) for improved lamb survival? The same question can be asked of shedding out ewes and lambs immediately after lambing as McMillan \& Knight (1985) found no effect of slope on lamb survival when the ewes and lambs were transferred to $36-40^{\circ}$ slopes 24 hours after birth of the lambs on flatter, more favourable terrain.

\section{Returns from lamb survival}

To achieve a $25 \%$ return on investment (ROI) for every $\$ 10,000$ invested in improving the lambing environment, the lamb wastage rate must decrease by $2 \%$ (to $20 \%$ ) on the model 400 ha farm carrying $2200 \mathrm{MA}$ ewes. This is assuming an average lamb value at weaning of $\$ 1.30 / \mathrm{kg}$ live weight and corresponds to a lambing percentage of $132 \%$ (plus 3\%). $\$ 10,000$ was used as an investment figure as it represents a significant investment to be made in addressing environmental and management factors. It is sufficient to perhaps undertake either $1 \mathrm{~km}$ of conventional fencing, $2 \mathrm{~km}$ of drainage, or 500 spaced plantings. Whilst not accounting for the cost of capital, the farmer could expect to recoup the investment made over 4 years (based on a nominal ROI of $25 \%$ ). Using the paddock score and lamb docking percentage relationship in 2006 (Fig. 1a), by reducing the paddock score by 10 (as a result of the improvements made), we could expect an increase in lamb survival of approximately $10 \%$. This provides one example of how the LAT can be utilised by farmers to prioritise on-farm development and investment decisions. The LAT can also be used in a diagnostic mode, assisting for example in identifying paddocks with low scores, but with below average lambing percentages. 


\section{Conclusions}

A landscape assessment tool has been developed that allows farmers to objectively assess the risk of lambing multiple bearing ewes in particular paddocks on their farms. By qualifying the physical characteristics of a paddock, farmers are able to adopt alternative management plans or alter the environment to improve lamb survival and hence farm profitability. Increasing the survival of lambs from multiple bearing ewes will increase returns and addresses, at the same time, animal welfare issues that have the potential to cause major difficulties (trade barriers) in affluent overseas markets.

\section{ACKNOWLEDGEMENTS}

Those involved in the study including Garth Coleman, Nick Lansdown, Bryan Speedy, Nicola and Chris Smyth, John Robinson, John Linton, Murray Cammock, Bill and Russell Turner are a group of sheep farmers in North Island hill country with an eye to the future. The authors, along with the group of sheep and beef farmers, would like to thank MAF-SFF for funding this project as part of a large lamb survival project that included groups in other parts of the country.

\section{REFERENCES}

Agriculture and Forestry in New Zealand. 2003. An Overview A look at the Agriculture and Forestry industries in New Zealand November 2003 MAF. http://www.maf.govt.nz/mafnet/rural-nz/overview/ httoc.htm

Donnelly, J.R. 1984. The productivity of breeding ewes grazing on lucerne or grass and clover pastures on the Tablelands of Southern Australia Lamb mortality and weaning percentage. Australian Journal of Agricultural Research 35: 709-721.

Holst, P.J.; Cullis, B.R. 1982 Meteorological data as a management aid for the reduction of lamb losses from inclement weather. Animal Production in Australia 14: 432-434.

Knight, T.W.; McMillan, W.H.; Kilgor, R.; Hockey, H.U.P.; Hall, D.R. 1989 Effect of slope of lambing site and lamb mortality. New Zealand Journal of Agricultural Research 32: 199-206.

McMillan, W.H.; Knight, T.W. 1985. Effect of slope on lamb mortality. Proceedings of the New Zealand Society of Animal Production 45: 163-165. 